\title{
Thermal Equilibrium Dynamic Control Based on DPWM Dual-Mode Modulation of High Power NPC Three-Level Inverter
}

\author{
Shi-Zhou Xu and Feng-You He \\ Department of Information and Electrical Engineering, China University of Mining and Technology, Xuzhou 221116, China
}

Correspondence should be addressed to Feng-You He; hfy_cumt@263.net

Received 12 January 2016; Revised 6 April 2016; Accepted 10 April 2016

Academic Editor: Tarek Ahmed-Ali

Copyright (C) 2016 S.-Z. Xu and F.-Y. He. This is an open access article distributed under the Creative Commons Attribution License, which permits unrestricted use, distribution, and reproduction in any medium, provided the original work is properly cited.

\begin{abstract}
In some special applications of NPC three-level inverters, such as mine hoist, there exist special conditions of overloading during the whole hoisting process and large overload in starting stage, during which the power-loss calculation of power devices and thermal control are important factors affecting the thermal stability of inverters. The principles of SVPWM and DPWM were described in this paper firstly, based on which the dynamic power losses of the two modulations of hoist in single period were calculated. Secondly, a thermal equilibrium dynamic control based on DPMW dual-mode modulation was proposed, which can switch the modulation dynamically according to the change of dynamic power loss to realize dynamic control of power loss and thermal equilibrium of inverter. Finally, simulation and experiment prove the effectiveness of the proposed strategy.
\end{abstract}

\section{Introduction}

In recent years, with the increase of inverter capacity, the application of three-level inverters is becoming more and more widespread, and the control of mine hoist is one of the most important applications.

The traditional modulation is SVPWM and its basic principle is taking ideal flux circle of three-phase symmetric winding of motor, which uses balanced three-phase sine wave voltage as power supply, as references to switch power devices in three phases according to the established rules to form PWM waves, to implement the approximate track of actual flux vectors to ideal flux vectors. This method is mainly conducted by increasing the switching frequency to push the harmonic components to high frequency period and then use a small filter to filter these high harmonics realizing good output power quality and motor control performance. However, too high switching frequency brings in indispensable high power loss of power devices, which becomes particularly serious in mine hoist with high overload ratio and continuous working mode. Therefore, how to realize the thermal equilibrium dynamic control for this special condition has been a hot research topic in recent years.
In $[1,2]$, the three-level modulation was simplified by decomposing the space vector diagram of three-level voltage into six two-level space vector diagrams and through vector transform method to decrease the difficulty to two-level modulation level. However, this method is continuous PWM modulation and all the three-phase power devices will work in each sector, bringing in high switching power loss. A modulation principle of simplified three-level PWM was described in [3], which proves the high power loss of continuous PWM from the principle viewpoint. Discontinuous PWM (DPWM) modulation is also called dead zone PWM and bus-bar clamped PWM. Its basic principle is adding zero sequence component to modulation waveform to make it equal to the peak or negative peak of triangle waveform and make them have no intersection points to maintain the switching state unchanged. DPWM modulation strategy can only control power devices of two phases within certain sector and can reduce switching power loss of one phase compared with continuous PWM by 1/3 [4-7], and meanwhile, a kind of unified expression method from various discontinuous PWM modulations was introduced in $[4,6]$. What is more, [7] proposed a circuit level decoupling of three-level DPWM modulation strategy, which will select the largest 
absolute value by comparing the values of three phases and make it switch on for certain modulation time to reduce the switching power loss, but it did not analyze how to reduce quantitatively and figure out the reduction value. A high performance generalized DPWM algorithm was proposed in [8], which uses SVPWM in low modulation range and GDPWM in high modulation range, but it did not change the modulation algorithm according to the load and did not calculate the power loss of the proposed algorithm.

At present, there are many power-loss calculation and thermal analysis researches on single IGBT module and twolevel converters using PWM modulation algorithm [9-13]. However, when it comes to three-level inverter, the principle is different, and under same modulation, the power loss will be different too. In [14-16], the power-loss analysis of power devices in NPC three-level inverters using PWM modulation algorithm did not consider the influence caused by junction temperature on power loss, which generated certain error between calculation and experiment result. A fast powerloss and temperature simulation method was proposed in [17], with which a 3D thermal model of power module was established and used Fourier-based solution to describe the variation of temperature through the whole inverter power module structure as a function of time. The power losses of power devices in three-level inverter based on SVPWM were researched in [18], but the results are average ones and cannot express the dynamic power loss and figure out the power loss under different overload ratios. A dual-mode modulation of parallel $\mathrm{H}$-bridge module per-phase topology based on quasisquare wave (QSW) and PWM modulation was introduced in [19], which said that it can reduce power loss by $20-50 \%$, but the two modulations have a not very good performance in controlling motors and cannot meet the complicated working condition of mine hoist.

The aim of this work is to solve the thermal equilibrium problem of mine hoist using high power NPC threelevel inverter with large overload ratios according to its special working condition. Therefore, a thermal equilibrium dynamic control of high power NPC three-level inverter based on DPWM dual-mode modulation was proposed in this paper. Under this algorithm, the modulation mode can be changed dynamically in accordance with dynamic power loss of power devices under different working condition and control the power loss in balance during the whole working cycle. Meanwhile, the total power loss should be under the cooling capacity of inverter cooling system to maintain an excellent thermal stability. The principles of SPWM and DPWM were described in Section 2 and the dualmode modulation was introduced in Section 3. Dynamic power-loss calculation under different modulation modes was expressed in Section 3, and the experiment and conclusion were organized in Sections 4 and 5, respectively.

\section{Principles of SVPWM and DPWM}

The topology of three-level inverter is shown in Figure 1.

It is well known that the upper and lower bridge arms of three phases in two-level inverters are complementary and it has $2^{3}=8$ voltage vectors, which is shown in Figure 2 .

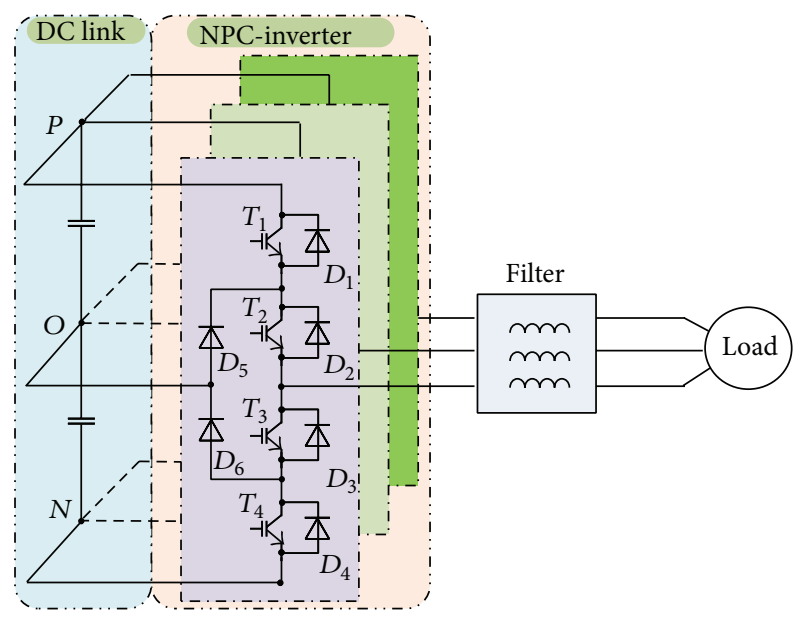

FIGURE 1: Topology of NPC three-level inverter.

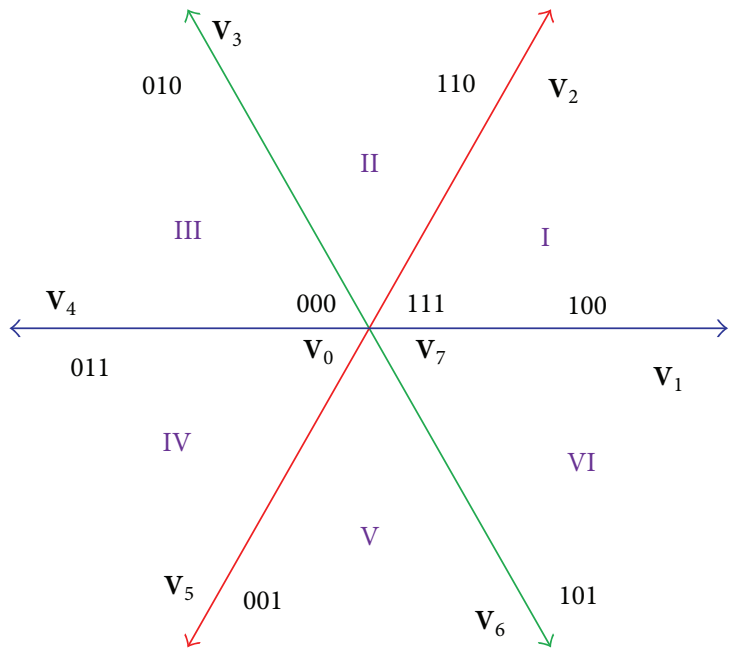

FIGURE 2: Space voltage vector diagram of two-level inverters.

Taking sector I as example, in one switching cycle $T_{0}$, the switching sequence of traditional SVPWM is shown in Figure 3. This distribution type is the one called zero vector dispersed method. It can be seen from the diagram that the two zero vectors $\mathbf{V}_{0(000)}$ and $\mathbf{V}_{7(111)}$ are distributed at both the ends and middle of switching cycle $T_{0}$, and each sector change only changes switching state in one phase, but in one switching cycle all the power devices of three phases will work [2]. The switching sequence of traditional SVPWM is shown in Figure 3.

It can be seen from Figure 3 that the tree-level space vector diagram can be considered as being composed of six two-level space vector diagrams, and every small hexagon takes the center of internal small hexagon as its vertex. Therefore, all we should do to simplify the tree-level voltage vector diagram into the two-level one is to shift all hexagons along the reverse direction of the vector pointing its center to the center of the big hexagon. In order to make the shifting correct, it is necessary to modify the synthetic reference vector. In Figure $4, V_{\text {ref }}$ is the reference vector, to be synthesized, of 


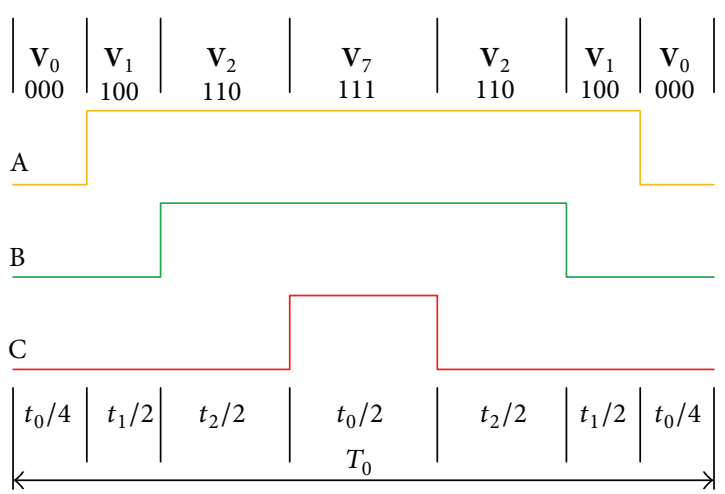

FIGURE 3: Switching sequence of traditional SVPWM.

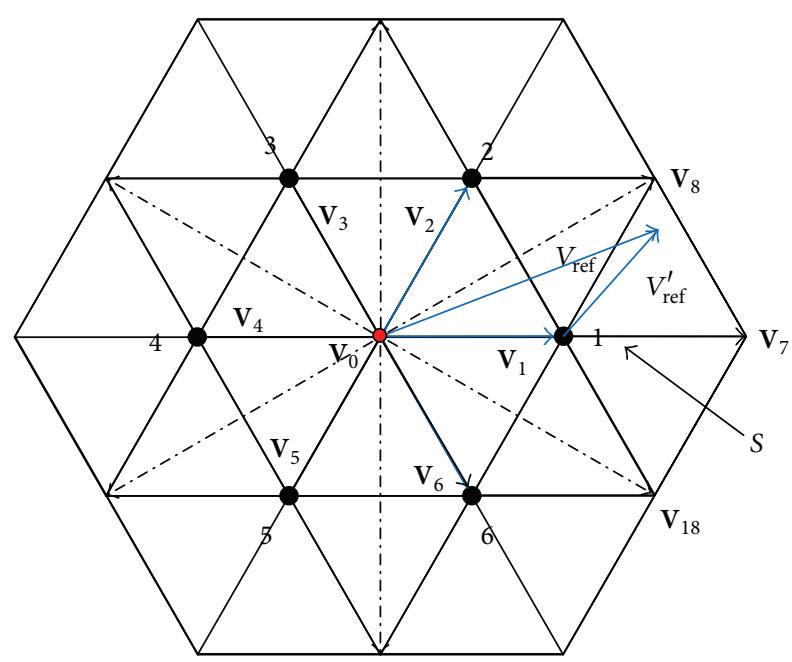

FIGURE 4: Space vectors of three-level inverter.

three-level inverter, which can be known from the diagram as $V_{\text {ref }}=\mathbf{V}_{1}+V_{\text {ref }}^{\prime}$, and $V_{\text {ref }}$ should subtract small hexagon center $\mathbf{V}_{1}$. In the same way, reference vectors of other hexagons should also subtract the corresponding small vector to obtain new reference vectors.

Discontinuous PWM modulation is different from traditional SVPWM in zero vectors' distribution. The zero vectors include $\mathbf{V}_{0(000)}$ and $\mathbf{V}_{7(111)}$, which will be corresponding to small vectors of three-level vector diagram. As shown in Figure 4 the whole diagram as a big hexagon is divided into 6 areas marked with $S=n(n=1,2,3,4,5$, and 6$)$, and $S$ is the center of each corresponding small hexagon, which transforms the three-level voltage space vectors into two-level ones. Therefore, we only need to research the small hexagon of two-level voltage space vectors to simplify the modulation calculation. The generalized discontinuous PWM scheme for two-level three-phase voltage source inverters is shown in [4]. Under the same $S$ value, each phase only switches between 1 and 0 or 0 and -1 and does not switch through 1,0 , and -1 . What is more, when $S=1$, phase A switches between 1 and 0 , and phase $\mathrm{B}$ switches between 0 and -1 . Therefore, as shown in Figure 4, when $S=1$, phase A switches on $T_{2}$ and switches off $T_{4}$ and only leaves $T_{1}$ and $T_{3}$ to modulate
TABLE 1: DPWMMIN switching sequence $(S=1$, sector I).

\begin{tabular}{lccccc}
\hline Two-level & 101 & 100 & 000 & 100 & 101 \\
\hline Three-level & $1-10$ & $1-1-1$ & $0-1-1$ & $1-1-1$ & $1-10$ \\
\hline
\end{tabular}

TABLE 2: DPWMMAX switching sequence $(S=1$, sector I).

\begin{tabular}{lccccc}
\hline Two-level & 100 & 101 & 111 & 101 & 100 \\
\hline Three-level & $1-1-1$ & $1-10$ & 100 & $1-10$ & $1-1-1$ \\
\hline
\end{tabular}

TABLE 3: Parameters of winding asynchronous motor.

\begin{tabular}{lc}
\hline Rated power $\mathrm{Pd}(\mathrm{kW})$ & 475 \\
Stator voltage $U_{s}(\mathrm{~V})$ & 6000 \\
Stator current $I_{d}(\mathrm{~A})$ & 59 \\
Rotor voltage $U_{r}(\mathrm{~V})$ & 640 \\
Rotor current $I_{r}(\mathrm{~A})$ & 435 \\
Rated speed $(\mathrm{r} / \mathrm{min})$ & 735 \\
Power factor & 0.85 \\
\hline
\end{tabular}

TABLE 4: Components parameters of inverter main circuit.

\begin{tabular}{lc}
\hline$U_{\mathrm{dc}}$ & $1100 \mathrm{~V}$ \\
DC-link capacitor parameters & $1800 \mu \mathrm{F} / 1300 \mathrm{~V}$ \\
Power device parameters & Infineon, FF1400R17IE4 series \\
Switching frequency & $2000 \mathrm{~Hz}$ \\
\hline
\end{tabular}

the outputs; phase B switches off $T_{1}$ and switch on $T_{3}$ and only leaves $T_{2}$ and $T_{4}$ to modulate the outputs; phase $C$ switches off $T_{1}$ and switch on $T_{3}$ and only leaves $T_{2}$ and $T_{4}$ to modulate the outputs.

It can be known by observing Figure 4 that reference vector $V_{\text {ref }}$ is in $S=1$ sector and the modified one $V_{\text {ref }}^{\prime}$ is in I sector in two-level vector diagram, which is composed of $\mathbf{V}_{7(1-1-1)}, \mathbf{V}_{8(10-1)}$, and $\mathbf{V}_{1(0-1-1)}$. What is more, $\mathbf{V}_{7(1-1-1)}$ and $\mathbf{V}_{8(10-1)}$ are the effective vectors, and $\mathbf{V}_{1(0-1-1)}$ act as the zero vector $\mathbf{V}_{0(000)}$ of two-level modulation algorithm. The small vector $\mathbf{V}_{1}$ has two switching states, (0-1-1) and (100), and when $S=1$, the switching state corresponding to zero vector $\mathbf{V}_{0(000)}$ is (0-1-1).

There are two two-level DPWM modulations, and both of them use one zero vector, which is distributed in the middle of switching sequence. One of them uses zero vector $\mathbf{V}_{0(000)}$, named as DPWMMIN, and the other uses zero vector $\mathbf{V}_{7(111)}$, named as DPWMMAX.

When it comes to sector I, the three-level DPWM switching sequences corresponding to DPWMMIN and DPWMMAX are shown in Tables 1 and 2.

It can be seen from Tables 1 and 2 that the two zero vectors are placed in the middle and the middle of two threelevel sequences is the small vector $\mathbf{V}_{1}$, which are $\mathbf{V}_{1(0-1-1)}$ and $\mathbf{V}_{1(100)}$, respectively.

\section{Dynamic Power-Loss Calculation}

Induction motor and inverter parameters are shown in Tables 3 and 4 , respectively. 


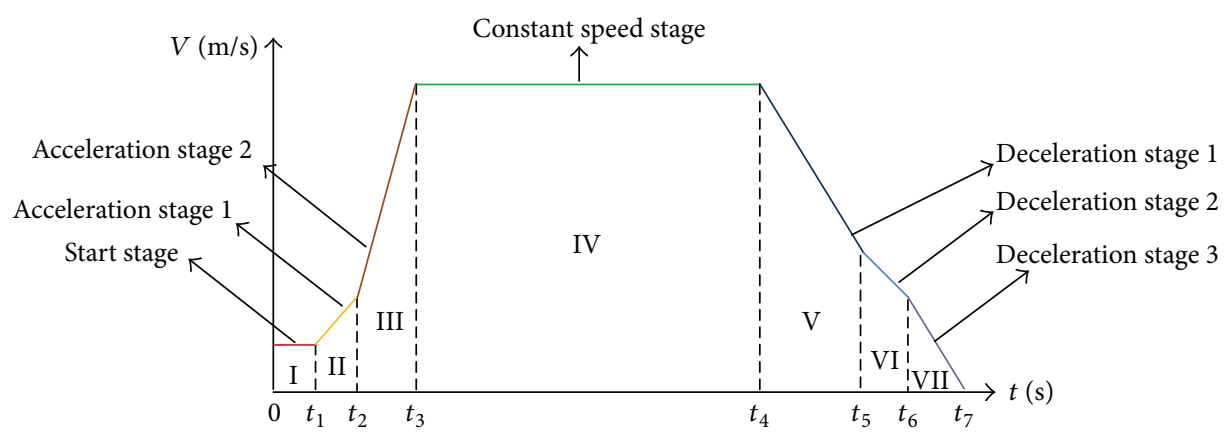

FIGURE 5: Speed curve.

TABLE 5: Parameters of all stages.

\begin{tabular}{lccccccc}
\hline & I & II & III & IV & V & VI & VII \\
\hline Acceleration $a\left(\mathrm{~m} / \mathrm{s}^{2}\right)$ & 0 & 0.3 & 0.5 & 0 & -0.47 & -0.09 & 0 \\
Height $S(\mathrm{~m})$ & 0.6 & 3.7 & 28.6 & 272 & 35 & 5 & 0.5 \\
Time $t(\mathrm{~s})$ & 3 & 4.33 & 7 & 46.9 & 10.5 & 7.7 & 2 \\
Current $(\mathrm{A})$ & 783 & 652 & 522 & 435 & 522 & 522 & 522 \\
\hline
\end{tabular}

The well depth is $348 \mathrm{~m}$. Meanwhile, the speed curve of one lifting cycle is shown in Figure 5.

It can be found by analyzing speed curve and corresponding parameters in Figure 5 and Table 5 that in the start stage of mine hoist the overload ratio is 1.8 times; in acceleration stages 1 and 2 , the acceleration direction is along the ascending direction, known as positive acceleration, and the overload ratios are 1.5 and 2 times, while in deceleration stages 1,2 , and 3, the acceleration direction is opposite to the ascending direction, known as negative acceleration, and the overload ratio is 1.2 times.

Because of the ramp function set in the process of invert current output, the currents in all stages change linearly, and the current functions are as follows.

Current function $I_{s}$ of start stage is

$$
I_{s}=783 \quad(0<t \leq 3) .
$$

Current function $I_{a 1}$ of acceleration stage 1 is

$$
I_{a 1}=652-30.02 t \quad(3<t \leq 7.33) .
$$

Current function $I_{a 2}$ of acceleration stage 2 is

$$
I_{a 2}=522-12.43 t \quad(7.33<t \leq 14.33) \text {. }
$$

Current function $I_{c}$ of constant speed stage is

$$
I_{c}=435 \quad(14.33<t \leq 61.23) \text {. }
$$

Current function of three deceleration stages is

$$
I_{d}=435+4.31 t \quad(61.23<t \leq 81.43) .
$$

It can be seen from (1)-(5) that the currents change with time, and the power loss changes with output condition under certain modulation. The traditional method to calculate

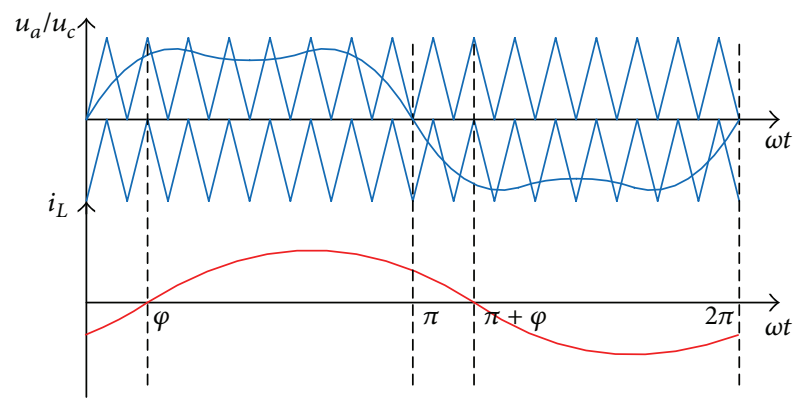

Figure 6: Phase relationship between equivalent modulation voltage and load current under SVPWM modulation.

power loss is to calculate the average value under certain period, which cannot describe the dynamic power loss and cannot perform thermal equilibrium control of power devices. So in this part the principle of average power-loss calculation will be derived and then deduced into dynamic power-loss calculation method in accordance with mine hoist parameters.

SVPWM modulation of NPC three-level inverter is realized on the basis of space vector synthesis, and phase relationship between equivalent modulation voltage and load current under SVPWM modulation is shown in Figure 6. It must be pointed out that Figure 6 is based on the double modulation wave carrier PWM strategy, which uses the central symmetry of output voltage vectors in three-level inverters. As shown in $[20,21]$, the three-level inverter outputs three kinds of level states; two carrier waves are needed to compare with modulation wave in this strategy, which is called positive and negative double carrier. Under this strategy, the calculation amount can be reduced compared with conventional modulation strategies.

Even though it can calculate power loss of power devices in every discrete switching cycle, it must calculate it for several times. What is worse, the duty ratio in each switching cycle is changing and cannot calculate them as SPWM using modulation function. But SVPWM can be equaled by injecting third harmonic into sinusoidal reference modulation voltage of SPWM. Equivalent modulation voltage function under SVPMW modulation can be expressed as follows:

$$
D(\alpha)=m \sin \alpha+\frac{1}{6} m \sin 3 \alpha,
$$


where $D(\alpha)$ is the modulation function; $m$ is the modulation depth; $\alpha$ is the phase angle of modulation function.

According to [18], the power losses of $T_{1}, D_{1}, T_{2}, D_{2}$, and $D_{5}$ of upper bridge arm in phase A based on SVPWM modulation under unity power factor can be obtained as follows:

$$
\begin{aligned}
& P_{\mathrm{con}, T_{1}}^{\mathrm{npc}, \mathrm{svpwm}}=\frac{m v_{0, T_{1}} I_{m}}{4 \pi}\left((\pi-\varphi) \cos \varphi+\frac{9}{8} \sin \varphi\right. \\
& \left.-\frac{1}{24} \sin 3 \varphi\right)+\frac{m r_{T_{1}} I_{m}^{2}}{4 \pi}\left(\frac{19}{18}+\frac{4}{3} \cos \varphi\right. \\
& \left.+\frac{7}{30} \cos 2 \varphi-\frac{2}{45} \cos 3 \varphi\right) \\
& P_{\mathrm{sw}, T_{1}}^{\mathrm{npcspwm}}=\frac{f_{\mathrm{sw}}}{2 \pi}\left(A_{\mathrm{sw}, T} I_{m}^{2} \frac{1}{2}\left(\pi-\varphi+\frac{1}{2} \sin 2 \varphi\right)\right. \\
& \left.+B_{\mathrm{sw}, T} I_{m}(1+\cos \varphi)+C_{\mathrm{sw}, T}(\pi-\varphi)\right) \\
& \cdot\left(\frac{U_{\mathrm{dc}} / 2}{U_{\text {base }}}\right)^{D_{\mathrm{sw}, T}}\left(\frac{T_{\mathrm{vj}, T_{1}}}{T_{\text {base }}}\right)^{K_{\mathrm{sw}, T}} \\
& P_{\mathrm{con}, D_{1}}^{\mathrm{npc,svpwm}}=\frac{m v_{0, D_{1}} I_{m}}{4 \pi}\left(\frac{9}{8} \sin \varphi-\varphi \cos \varphi\right. \\
& \left.-\frac{1}{24} \sin 3 \varphi\right)+\frac{m r_{D_{1}} I_{m}^{2}}{4 \pi}\left(\frac{19}{18}-\frac{4}{3} \cos \varphi\right. \\
& \left.+\frac{7}{30} \cos 2 \varphi+\frac{2}{45} \cos 3 \varphi\right) \\
& P_{\mathrm{rec}, D_{1}}^{\mathrm{npc,svpwm}}=\frac{f_{\mathrm{sw}}}{2 \pi}\left(A_{\mathrm{rec}, D} I_{\mathrm{pk}}^{2} \frac{1}{2}\left(\varphi-\frac{1}{2} \sin 2 \varphi\right)\right. \\
& \left.+B_{\mathrm{rec}, D} I_{\mathrm{pk}}(1-\cos \varphi)+C_{\mathrm{rec}, D} \varphi\right) \cdot\left(\frac{U_{\mathrm{dc}} / 2}{U_{\mathrm{base}}}\right)^{D_{\mathrm{rec}, D}} \\
& \cdot\left(\frac{T_{\mathrm{vj}, D_{1}}}{T_{\text {base }}}\right)^{K_{\mathrm{rec}, D}} \\
& P_{\text {con, } T_{2}}^{\mathrm{npc,svpwm}}=\frac{v_{0, T_{2}} I_{m}}{\pi}+\frac{r_{T_{2}} I_{m}^{2}}{4}-\frac{m v_{0, T_{2}} I_{m}}{4 \pi}\left(\frac{9}{8} \sin \varphi\right. \\
& \left.-\varphi \cos \varphi-\frac{1}{24} \sin 3 \varphi\right)-\frac{m r_{T_{2}} I_{m}^{2}}{4 \pi}\left(\frac{19}{18}-\frac{4}{3} \cos \varphi\right. \\
& \left.+\frac{7}{30} \cos 2 \varphi+\frac{2}{45} \cos 3 \varphi\right) \\
& P_{\mathrm{sw}, T_{2}}^{\mathrm{npc,svpwm}}=\frac{f_{\mathrm{sw}}}{2 \pi}\left(A_{\mathrm{sw}, T} I_{m}^{2} \frac{1}{2}\left(\varphi-\frac{1}{2} \cdot \sin 2 \varphi\right)\right. \\
& \left.+B_{\mathrm{sw}, T} I_{m}(1-\cos \varphi)+C_{\mathrm{sw}, T} \varphi\right) \cdot\left(\frac{U_{\mathrm{dc}} / 2}{U_{\mathrm{base}}}\right)^{D_{\mathrm{sw}, T}} \\
& \cdot\left(\frac{T_{\mathrm{vj}, T_{2}}}{T_{\text {base }}}\right)^{K_{\mathrm{sw}, T}}
\end{aligned}
$$

$$
\begin{aligned}
& P_{\text {con }, D_{2}}^{\mathrm{npc}, \mathrm{svpwm}}=\frac{m v_{0, D_{2}} I_{m}}{4 \pi}\left(\frac{9}{8} \sin \varphi-\varphi \cos \varphi\right. \\
& \left.\quad-\frac{1}{24} \sin 3 \varphi\right)+\frac{m r_{D_{2}} I_{m}^{2}}{4 \pi}\left(\frac{19}{18}-\frac{4}{3} \cos \varphi\right. \\
& \left.\quad+\frac{7}{30} \cos 2 \varphi+\frac{2}{45} \cos 3 \varphi\right), \\
& P_{\mathrm{rec}, D_{2}}^{\mathrm{npcspwm}}=0, \\
& P_{\mathrm{con}, D_{5}}^{\mathrm{npc}, \mathrm{svpwm}}=\frac{v_{0, D_{5}} I_{m}}{\pi}+\frac{r_{D_{5}} I_{m}^{2}}{4}-\frac{m r_{D_{5}} I_{m}^{2}}{2 \pi}\left(\frac{19}{18}\right. \\
& \left.\quad+\frac{7}{30} \cos 2 \varphi\right)-\frac{m v_{0, D_{5}} I_{m}}{2 \pi}\left(\frac{1}{2} \pi \cos \varphi-\varphi \cos \varphi\right. \\
& \left.\quad+\frac{9}{8} \sin \varphi-\frac{1}{24} \sin 3 \varphi\right), \\
& \quad+\left(\frac{U_{\mathrm{dc}} / 2}{U_{\mathrm{base}}}\right) \\
& P_{\mathrm{rec}, D_{5}}^{\mathrm{npc}, \mathrm{sppwm}}=\frac{f_{\mathrm{sw}}}{2 \pi}\left(\frac{D_{\mathrm{rec}, D}}{A_{\mathrm{rec}, D} I_{m}^{2}} \frac{1}{2}\left(\pi-\varphi+\frac{1}{2} \sin 2 \varphi\right)\right. \\
& \left.\quad B_{\mathrm{rec}, D} I_{m}(1+\cos \varphi)+C_{\mathrm{rec}, D}(\pi-\varphi)\right) \\
& K_{\mathrm{rec}, D}
\end{aligned}
$$

So power losses of $T_{1}, D_{1}, T_{2}, D_{2}$, and $D_{5}$ of upper bridge arm in phase $\mathrm{A}$ are

$$
\begin{aligned}
& P_{T_{1}}^{\mathrm{npc,svpwm}}=P_{\mathrm{con}, T_{1}}^{\mathrm{npc,svpwm}}+P_{\mathrm{sw}, T_{1}}^{\mathrm{npc}, \mathrm{svpwm}}, \\
& P_{D_{1}}^{\mathrm{npc}, \mathrm{svpwm}}=P_{\mathrm{con}, D_{1}}^{\mathrm{npc,svpwm}}+P_{\mathrm{rec}, D_{1}}^{\mathrm{npc}, \mathrm{svpwm}}, \\
& P_{T_{2}}^{\mathrm{npc}, \mathrm{svpwm}}=P_{\mathrm{con}, T_{2}}^{\mathrm{npc,svpwm}}+P_{\mathrm{sw}, T_{2}}^{\mathrm{npc}, \mathrm{svpwm}} \text {, } \\
& P_{D_{2}}^{\text {npc,svpwm }}=P_{\text {con }, D_{2}}^{\text {npc,svpwm }}+P_{\text {rec, }, D_{2}}^{\text {npc,svpwm }}, \\
& P_{D_{5}}^{\mathrm{npc}, \mathrm{svpwm}}=P_{\mathrm{con}, D_{5}}^{\mathrm{npc}, \mathrm{svpwm}}+P_{\mathrm{rec}, D_{5}}^{\mathrm{npc}, \mathrm{svpwm}} .
\end{aligned}
$$

Because of the symmetry of upper and lower bridge arm, the total power loss $P_{\text {total }}^{\text {npcsvewm }}$ of NPC three-level inverter under SVPWM modulation can be expressed as

$$
\begin{aligned}
& P_{\text {total }}^{\text {npcspwm }}=6\left(P_{T_{1}}^{\text {npc,svpwm }}+P_{D_{1}}^{\text {npc,svpwm }}+P_{T_{2}}^{\text {npc,svpwm }}\right. \\
& \left.\quad+P_{D_{2}}^{\text {npcsvpwm }}+P_{D_{5}}^{\text {npc,svpwm }}\right) .
\end{aligned}
$$

In (6)-(18), $\varphi$ is the load impedance angle; $A_{\mathrm{rec}, D}, B_{\mathrm{rec}, D}$, and $C_{\text {rec, } D}$ are quadratic curve fitting coefficient of switching power loss changing with current under testing conditions; $D_{\text {rec, } D}$ is the correction coefficient of testing voltage $U_{\text {base; }}$; $K_{\text {rec,D }}$ is the correction coefficient of testing junction temperature $T_{\text {base }} ; v_{0, T_{x}}=v_{0, T_{-} 25^{\circ} \mathrm{C}}+K_{v_{0}, T}\left(T_{\mathrm{vj}, T_{x}}-25^{\circ} \mathrm{C}\right)$ stands for initial saturation voltage drop of the $x$ th IGBT; $r_{T_{x}}=$ $r_{T \_25^{\circ} \mathrm{C}}+K_{r, T}\left(T_{\mathrm{vj}, T_{x}}-25^{\circ} \mathrm{C}\right)$ stands for conducting resistance of the $x$ th IGBT; $v_{0, D_{x}}=v_{0, D-25^{\circ} \mathrm{C}}+K_{v_{0}, D}\left(T_{\mathrm{vj}, D_{x}}-25^{\circ} \mathrm{C}\right)$ stands for initial saturation voltage drop of the $x$ th fast recovery diode; $r_{D_{x}}=r_{D_{-} 25^{\circ} \mathrm{C}}+K_{r, D}\left(T_{\mathrm{vj}, D_{x}}-25^{\circ} \mathrm{C}\right)$ stands for conducting 
resistance of the fast recovery diode; $T_{\mathrm{vj}, D_{x}}$ stands for junction temperature of the fast recovery diode, where $x=1,2$, and $5 ; P_{\text {con, } T_{1}}^{\text {npc,spwm }}, P_{\text {con, }, D_{1}}^{\text {npc,spwm }}, P_{\text {con, }, T_{2}}^{\text {npc,svpm }}, P_{\text {con, }, D_{2}}^{\text {npc,svpwm }}$, and $P_{\text {con, }, D_{5}}^{\text {npc,svpwm }}$ are the conducting power losses of $T_{1}, D_{1}, T_{2}, D_{2}$, and $D_{5}$, respectively; $P_{\mathrm{sw}, T_{1}}^{\mathrm{npc}, \mathrm{spwm}}$ and $P_{\mathrm{sw}, T_{2}}^{\mathrm{npc}, \mathrm{svpw}}$ are the switching power losses of $T_{1}$ and $T_{2} ; P_{\text {rec, }, D_{1}}^{\text {npcsvwm }}, P_{\text {rec, }, D_{2}}^{\text {npc,spm }}$, and $P_{\text {rec, } D_{5}}^{\text {npc,svpwm }}$ are the reverse recovery power losses of $D_{1}, D_{2}$, and $D_{5}$.

In [22], the double-fed mine hoist model was built and analyzed. For motor load, modulation depth $m$ in (6) under certain speed is fixed, and the impedance angle is a constant value under certain speed operating in unit power factor state by compensating power factor on stator side. Therefore, it can be defined that

$$
\begin{aligned}
& X=\frac{m v_{0, D_{1}}}{4 \pi}\left(\frac{9}{8} \sin \varphi-\varphi \cos \varphi-\frac{1}{24} \sin 3 \varphi\right) \\
& Y=\frac{m r_{D_{1}}}{4 \pi}\left(\frac{19}{18}-\frac{4}{3} \cos \varphi+\frac{7}{30} \cos 2 \varphi+\frac{2}{45} \cos 3 \varphi\right) .
\end{aligned}
$$

It can be seen from (19) that, under certain speed, $X$ and $Y$ are two constants generated by the fixed value of modulation depth $m$ and load impedance angle; under different speeds, the values of $X$ and $Y$ can be transformed into the function of $I_{m}$ and figured out according to the speed curve in Figure 5.

Put $X$ and $Y$ into (7), and it will be transformed as follows:

$$
P_{\mathrm{con}, T_{1}}^{\mathrm{npc}, \mathrm{svpwm}}=X \cdot I_{m}+Y \cdot I_{m}^{2} .
$$

Right now, $P_{\text {con, } T_{1}}^{\text {npcsvwm }}$ will be a dynamic power loss changing with output current of inverter. Put (1)-(5) into (20), and the following functions can be obtained.

In start stage, conducting power loss $P_{\mathrm{con}, T_{1}-s}^{\mathrm{npc}, \mathrm{svpwm}}$ of $T_{1}$ can be expressed as

$$
P_{\text {con, } T_{1} s}^{\text {npcsvpw }}=783 X+613089 Y \quad(0<t \leq 3) .
$$

In acceleration stage 1 , conducting power loss $P_{\text {con, }, T_{1}-a 1}^{\text {npc,svpm }}$ of $T_{1}$ can be expressed as

$$
\begin{aligned}
P_{\text {con, }, T_{1} a 1}^{\text {np,supwm }}= & 901.2004 \cdot Y \cdot t^{2} \\
& -(30.02 \cdot X+39146.08 \cdot Y) \cdot t \\
& +(625 \cdot X+425104 \cdot Y)
\end{aligned}
$$

$$
(3<t \leq 7.33) .
$$

Define quadratic term coefficient $901.2004 \cdot Y=X_{a 1}^{\prime}$, and monomial coefficient $-(30.02 \cdot X+39146.08 \cdot Y)=Y_{a 1}^{\prime}$, constant term $(625 \cdot X+425104 \cdot Y)=Z_{a 1}^{\prime}$, and (22) will be transformed into

$$
P_{\text {con, }, T_{1}-a 1}^{\mathrm{npc}, \mathrm{svpwm}}=X_{a 1}^{\prime} \cdot t^{2}+Y_{a 1}^{\prime} \cdot t+Z_{a 1}^{\prime} \quad(3<t \leq 7.33) .
$$

In acceleration stage 2 , conducting power loss $P_{\text {con, }, T_{1}-a 2}^{\mathrm{npc}, \mathrm{svpwm}}$ of $T_{1}$ can be expressed as

$$
P_{\text {con, }, T_{1}-a 2}^{\mathrm{npcspwm}}=X_{a 2}^{\prime} \cdot t^{2}+Y_{a 2}^{\prime} \cdot t+Z_{a 2}^{\prime}
$$

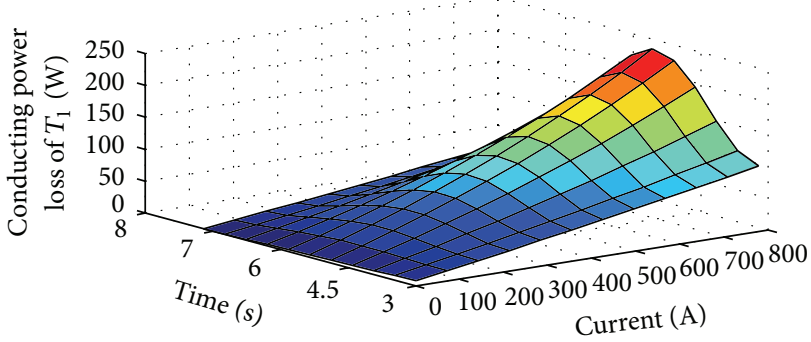

FIgURE 7: Dynamic conducting power loss of $T_{1}$ in range $(3,7.33]$.

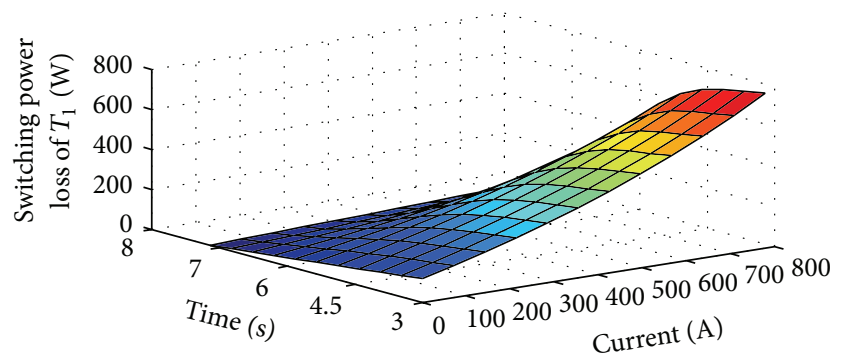

FIgURE 8: Dynamic switching power loss of $T_{1}$ in range $(3,7.33]$.

In constant speed stage, conducting power loss $P_{\text {con, } T_{1-} \text { npw }}^{\text {now }}$ of $T_{1}$ can be expressed as

$$
P_{\text {con }, T_{1} c}^{\mathrm{npc}, \mathrm{svpwm}}=435 X+189225 Y \quad(14.33<t \leq 61.23) .
$$

In three deceleration stages, conducting power loss $P_{\text {con, } T_{1} d}^{\text {npc,svpwm }}$ of $T_{1}$ can be expressed as

$$
P_{\mathrm{con}, T_{1}-d}^{\mathrm{npc,svpwm}}=X_{d}^{\prime} \cdot t^{2}+Y_{d}^{\prime} \cdot t+Z_{d}^{\prime}
$$

$(61.23<t \leq 81.43)$.

It can be seen by (23), (24), and (26) that these three equations are unary quadratic equations with variable time $t$, which are continuously differentiable in their respective ranges. So all of them have the maximum in their ranges, corresponding to their maximum conducting power loss, which can be added to generate the maximum conducting power loss $P_{\text {con, } T_{1}}^{\text {npcspwm }}$ in single lifting cycle. In the same way, the maximum switching power loss $P_{\mathrm{sw}, T_{1}}^{\mathrm{npc}, \mathrm{svpwm}}$ in single lifting cycle can be obtained too. Both conducting and switching power loss make up the total power loss of $T_{1}$, which can be considered as the maximum heat source power during the cooling system design. In the following, range $(3,7.33$ ] will be taken as example, and all the parameters corresponding to all speed points are put into functions mentioned above. By using MATLAB, the relationship among dynamic conducting power loss of $T_{1}$, time, and current can be received as shown in Figure 7.

In the similar way, dynamic switching power loss of $T_{1}$ in range $(3,7.33$ ] can be acquired in Figure 8.

Similarly, dynamic power losses of $T_{1}$ in other ranges of the single lifting cycle can be obtained as shown in Figure 9. 


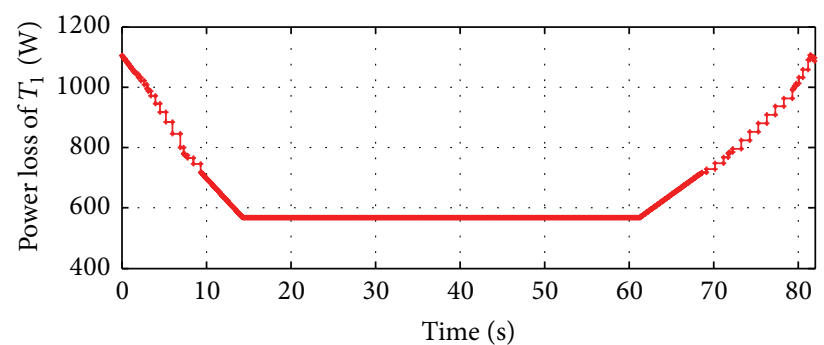

Figure 9: Dynamic total power loss of $T_{1}$ in single lifting cycle.

According to the same principle, dynamic power losses of $D_{1}, T_{2}, D_{2}$, and $D_{5}$ in upper bridge arm of phase A can be received in Figure 10.

Power losses in Figure 10 were calculated based on SVPWM modulation. It can be seen that in start and acceleration stages, power losses are much larger, especially acceleration stages, far more than that of constant speed stage and average loss of single lifting cycle. But due to low initial temperature of start and acceleration stages, the high temperature rise in them is covered up, and a great deal of heat will accumulate at constant speed and then be cooled down gradually, so there will be a high temperature phenomenon in constant speed period. As for power loss in deceleration period, it will not affect as much as other stages because of the existence of interval and will be ignored in this paper. For a repeat operating system, when the periodic working is not frequent enough, the power device temperatures will run into a dynamic balance, which has a close relationship with environment temperature, system power loss, and cooling system capacity. But when the cyclical operation is too frequent, plenty of heat generated in the start and acceleration stages will probably lead to explosion caused by thermal deposition in power devices, which will increase the system failure rate and reduce the service life of system. Therefore, for frequent periodic hoist condition, it is necessary to control the power loss dynamically and make the generated heat under the control of cooling system. It can be seen from [7] that, in one modulation voltage cycle, DPWM can reduce $1 / 3$ power loss comparing with SVPWM. It can be seen from (7) that $\varphi$ is a constant under certain load and $P_{\text {con, } T_{1}}^{\text {npcspm }}$ is decided by $\alpha$ only when the load current $I_{m}$ is fixed. $\alpha$ is the phase angle of the modulation function in (6), which can fix the duty cycle. Duty cycle is the only factor that decides the difference of conduction losses between SVPWM and DPWM. But upper and lower bridge arm is symmetrical, which means that, under DPWM modulation when the upper IGBT is switched on, the corresponding symmetrical IGBT in the lower bridge arm is switched off. Therefore the total conduction losses under DPWM modulation are the same as those values under SVPWM. So as in [7] only reduction of switching losses was considered in this paper. However, the DPWM modulation has a tiny poor performance in hoist control. So a dualmode modulation algorithm was proposed in this paper to keep both good performances, which uses DPWM in the low speed areas (I, II, and III sections) with low requirements on control performance and noise only to reduce power

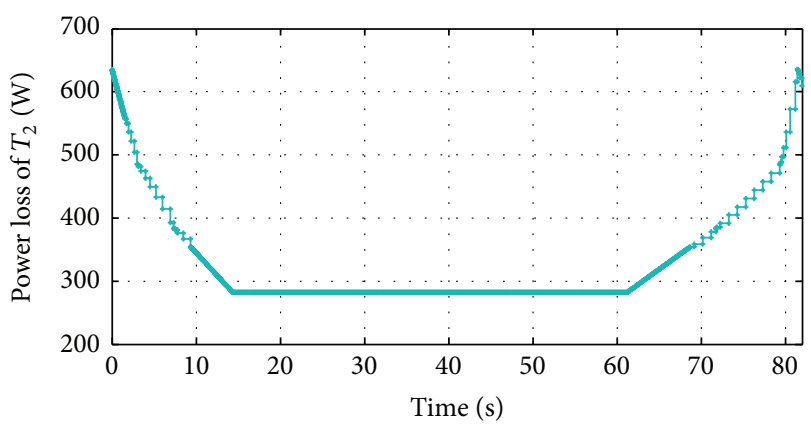

(a) Power loss of $T_{2}$

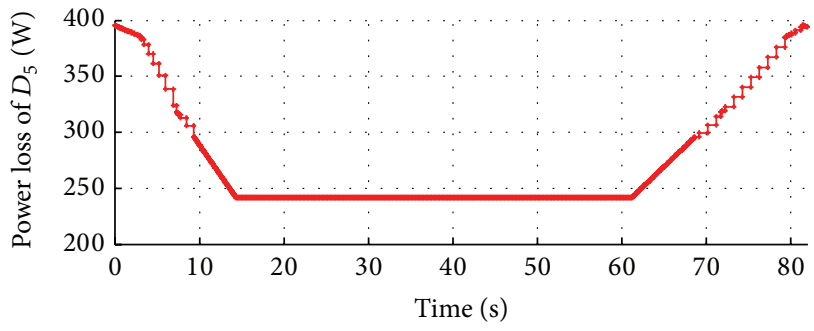

(b) Power loss of $D_{5}$

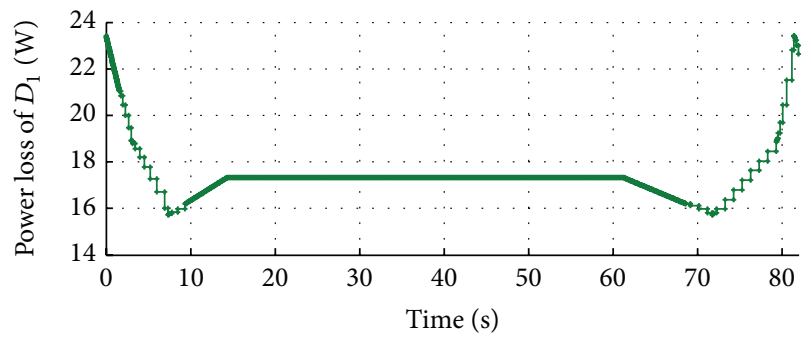

(c) Power loss of $D_{1}$

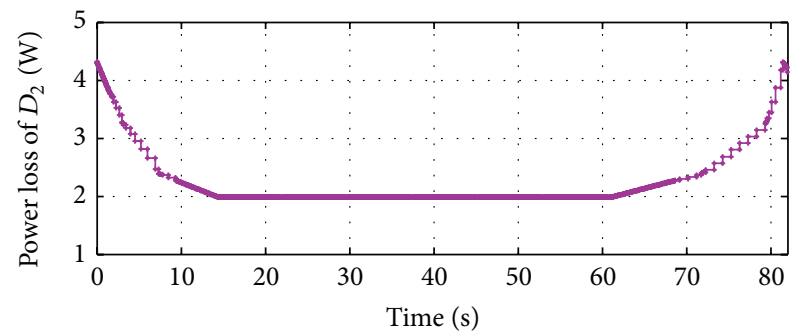

(d) Power loss of $D_{2}$

FIGURE 10: Dynamic power losses of power devices in upper bridge arm of phase A.

loss and uses SVPWM in constant speed and deceleration stage to keep high requirements on motor control and noise depression performance. Considering thermal hysteresis of cooling system, the switching time point of this modulation in one lifting cycle is the point $t=15 \mathrm{~s}$, and power losses of power devices under dual-mode modulation are shown in Figure 11.

The comparisons of junction temperatures between SVPMW and dual-mode modulation are shown in Figures 12-16.

It can be known by analyzing Figures $12-16$ that before $17 \mathrm{~s}$ temperatures under dual-mode modulation have a $6^{\circ} \mathrm{C}$ 


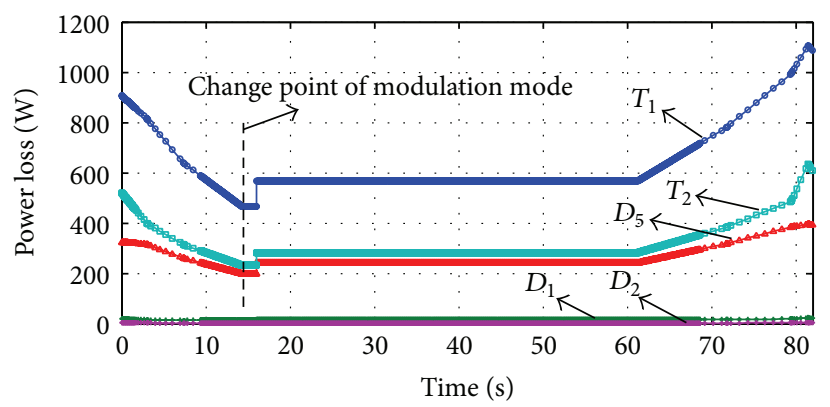

FIGURE 11: Power losses of power devices under dual-mode modulation.

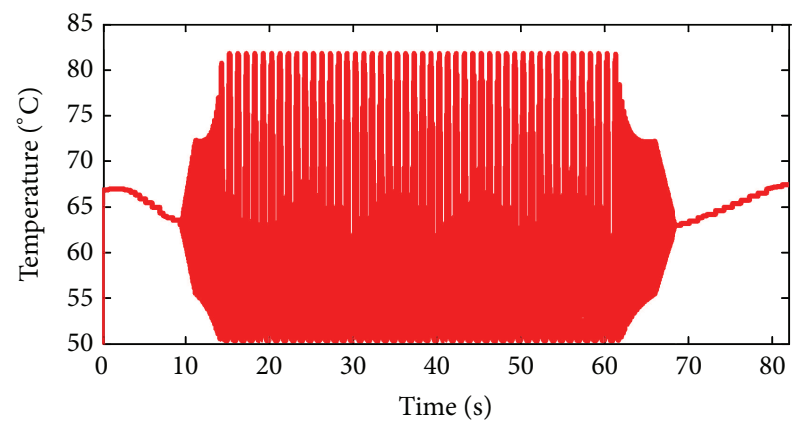

(a) Temperature under SVPWM modulation

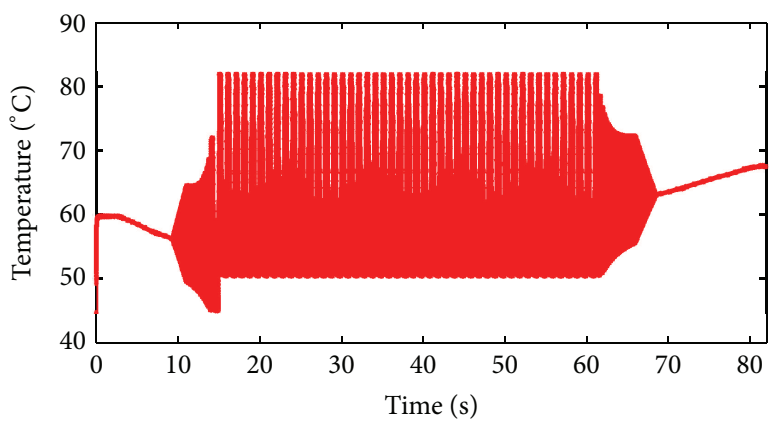

(b) Temperature under dual-mode modulation

Figure 12: Junction temperature of $D_{5}$.

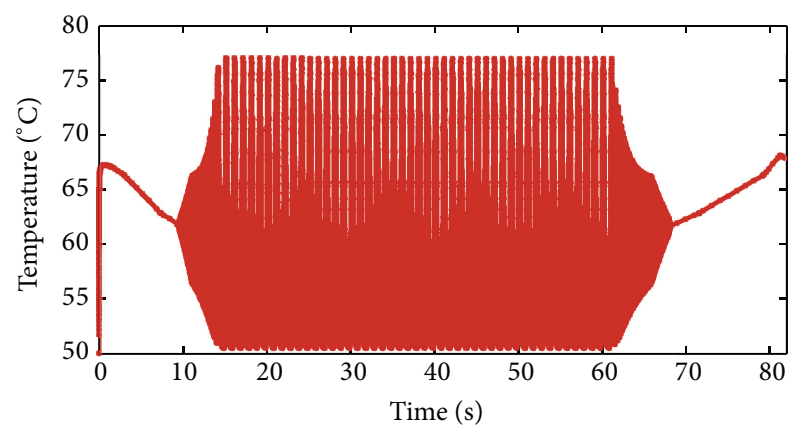

(a) Temperature under SVPWM modulation

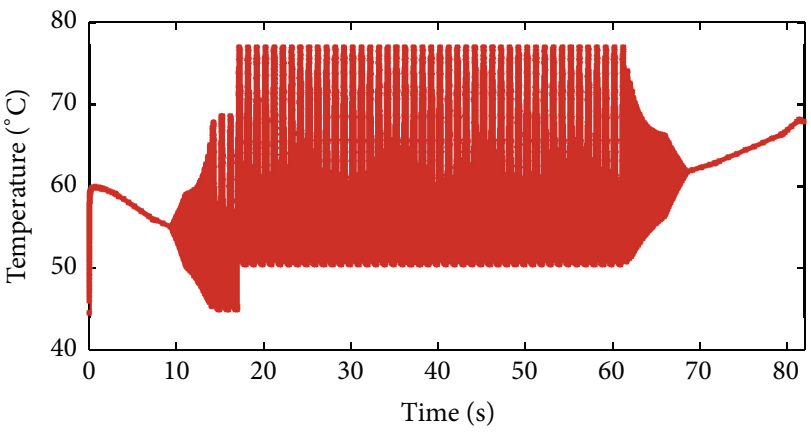

(b) Temperature under dual-mode modulation

Figure 13: Junction temperature of $T_{1}$.

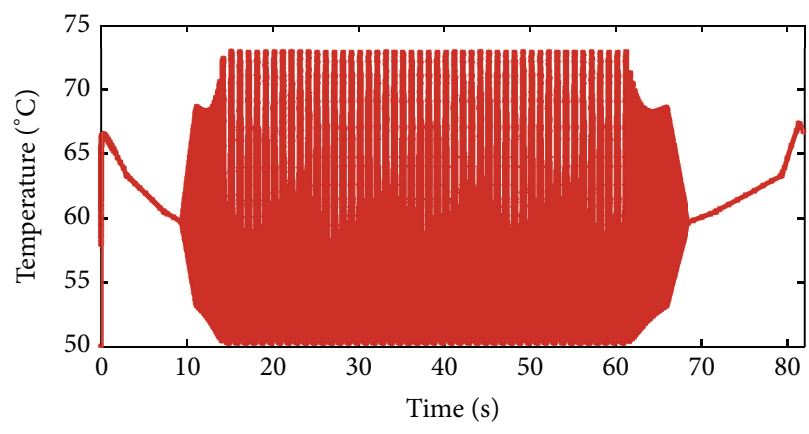

(a) Temperature under SVPWM modulation

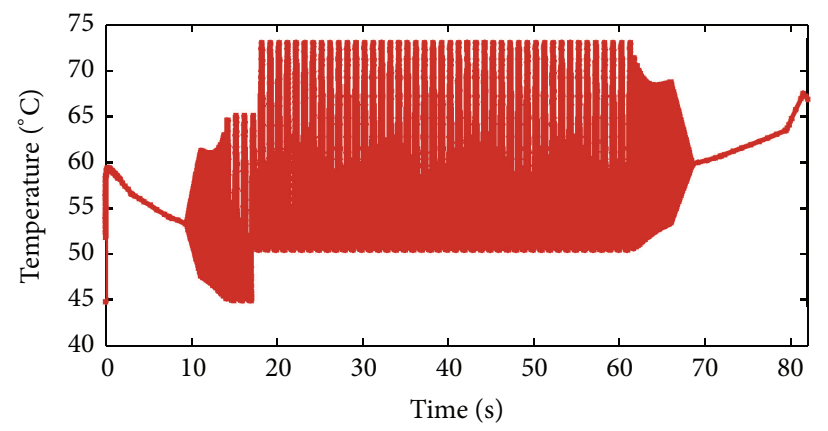

(b) Temperature under dual-mode modulation

FIGURE 14: Junction temperature of $T_{2}$. 


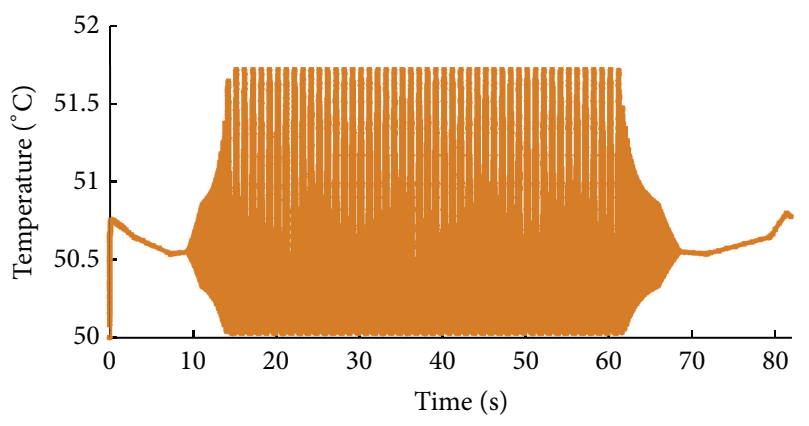

(a) Temperature under SVPWM modulation

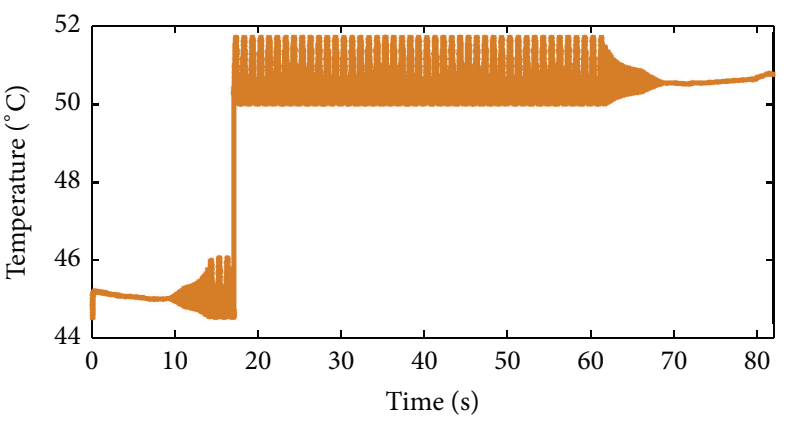

(b) Temperature under dual-mode modulation

Figure 15: Junction temperature of $D_{1}$.

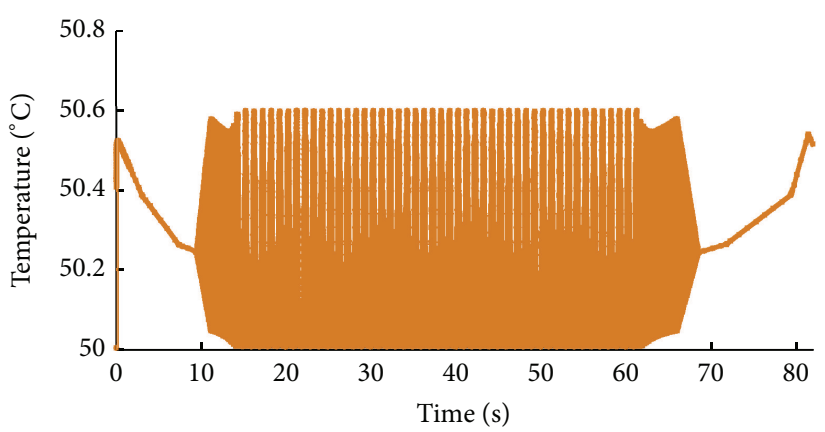

(a) Temperature under SVPWM modulation

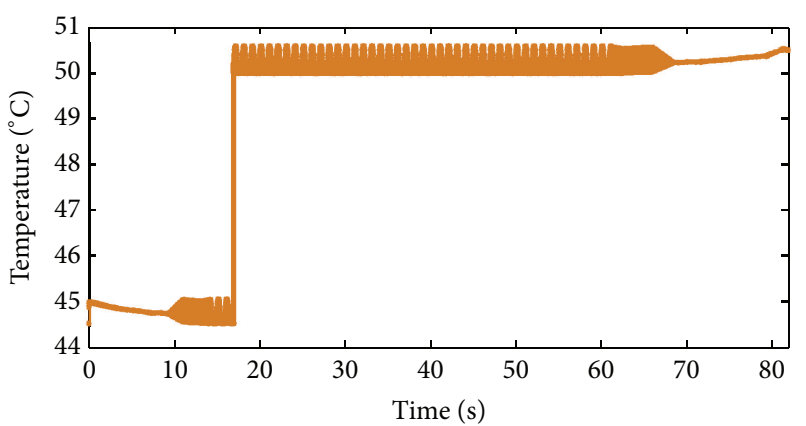

(b) Temperature under dual-mode modulation

FIGURE 16: Junction temperature of $D_{2}$.

advantage lower than the ones under SVPWM modulation, and the maximum curve density exists in the range from $t=10 \mathrm{~s}$ to $t=17 \mathrm{~s}$. But the simulation cannot show heat accumulation, and initial temperature of each simulation cycle is the fixed ambient time, which will cover the high temperature phenomenon of multiple periodic operation.

\section{Simulation and Experiment}

In this sector, temperature rise experiment was conducted based on dynamic power-loss calculation, and the experiment platform is shown in Figure 17.

In Figure 17, $\mathrm{ABC}$ stands for three phases of inverter, whose structure is shown in Figure 18.

In Figure 18, A, B, and $\mathrm{C}$ are the places fixing power module including heatsink and power devices, which is shown in Figure 19. Due to the short time of I, II, and III sections, it is difficult to observe dynamic thermal behavior in only one operation cycle, so a two-hour temperature rise experiment was conducted in this paper to ensure that the system is in steady state and then take the next cycle to make comparison experiment. The following simulation results are obtained based on the inverter structure and parameters.

It can be seen from Figure 20 that the maximum wind speed of heatsink inlet is $11.2 \mathrm{~m} / \mathrm{s}$. From Figures $21(\mathrm{a})$ and 21(b), it is known that the maximum substrate temperature of phase A upper bridge arm under SVPWM modulation in acceleration stages is $85^{\circ} \mathrm{C}$ approximately, and under DPWM it is $77^{\circ} \mathrm{C}$. The following experiment is conducted with the same parameters and conditions.

Experiment wind speed of heatsink inlet is shown in Figure 22, which is $11.19 \mathrm{~m} / \mathrm{s}$ and close to the simulation value. The switching point of two modulations in enlarged view is shown in Figure 23. It is shown in Figure 24 that, in the single hoist lifting cycle, the torque current has much more burrs in start and acceleration stages than constant and deceleration stages, which means that the control performance based on DPWM dual-mode modulation is tiny worse than SVPWM. From Figure 25, it is found that the substrate temperature based on DPWM modulation is lower than the one based on SVPWM by $8^{\circ} \mathrm{C}$ on average. What is more, the average substrate temperature based on SVPWM modulation has a $5^{\circ} \mathrm{C}$ error with simulation value, and the one based on DPWM dual-mode modulation has a $4^{\circ} \mathrm{C}$ error with simulation value. Temperatures of acceleration stages, shown in Figure 26, were obtained when the system was running in steady state and the temperature based on DPWM modulation was captured firstly, and meanwhile after one cycle the one based on SVPWM was gained. It is visible by analyzing that the DPWM dual-mode modulation can decrease the surface temperature of power module by $5^{\circ} \mathrm{C}$ compared with SVPWM modulation. From what has been discussed above, it is proved that 


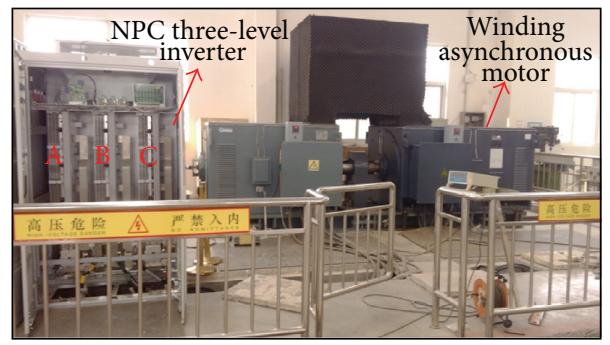

FIGURE 17: Experiment platform.

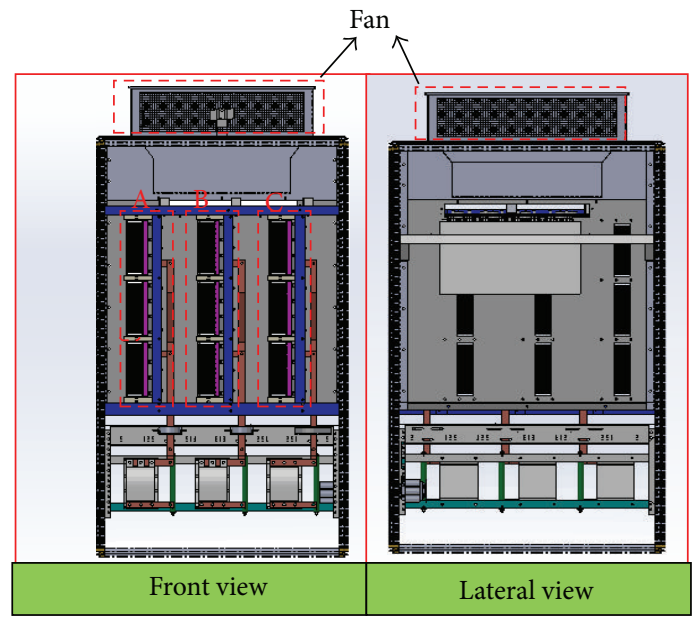

FIGURE 18: Structure of inverter.

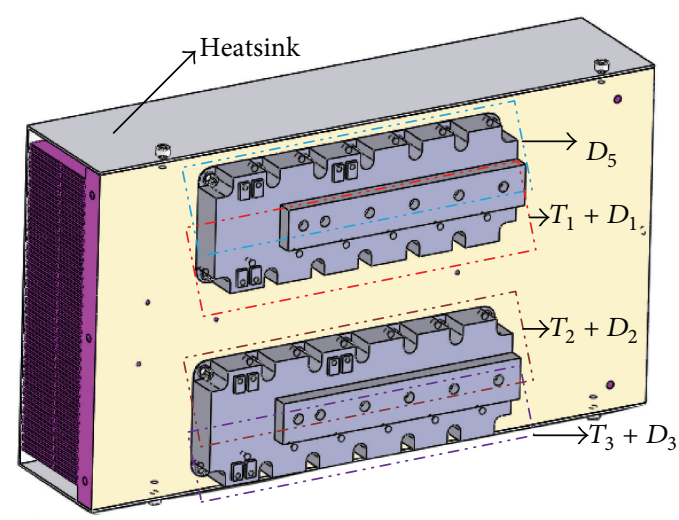

FIGURE 19: Distribution of power devices in phase A on heatsink.
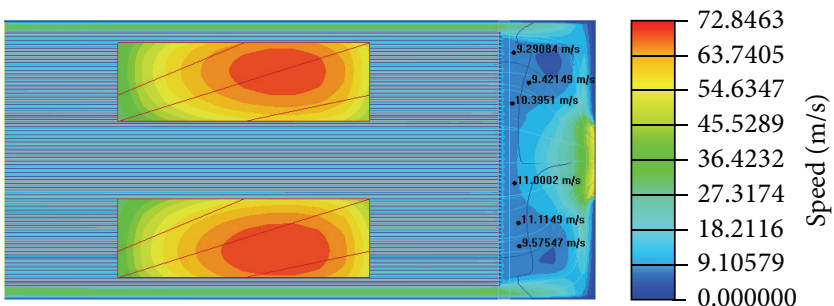

FIGURE 20: Simulation of heatsink wind speed. 


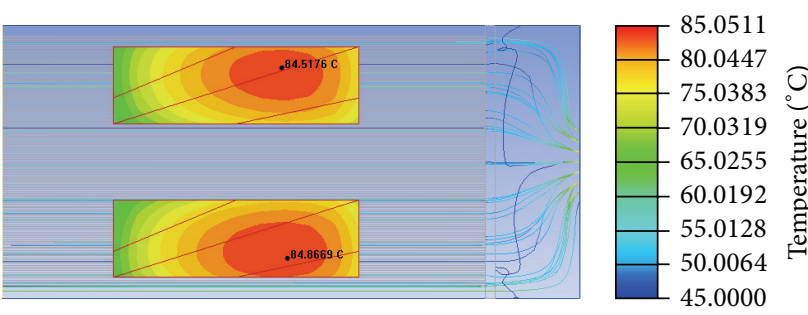

(a) Temperature simulation based on SVPWM

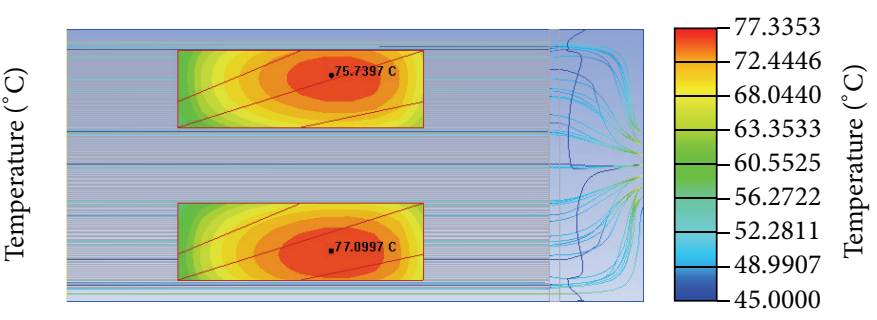

(b) Temperature simulation based on DPWM

FIgURE 21: Temperature simulation of power devices in phase A upper bridge arm.

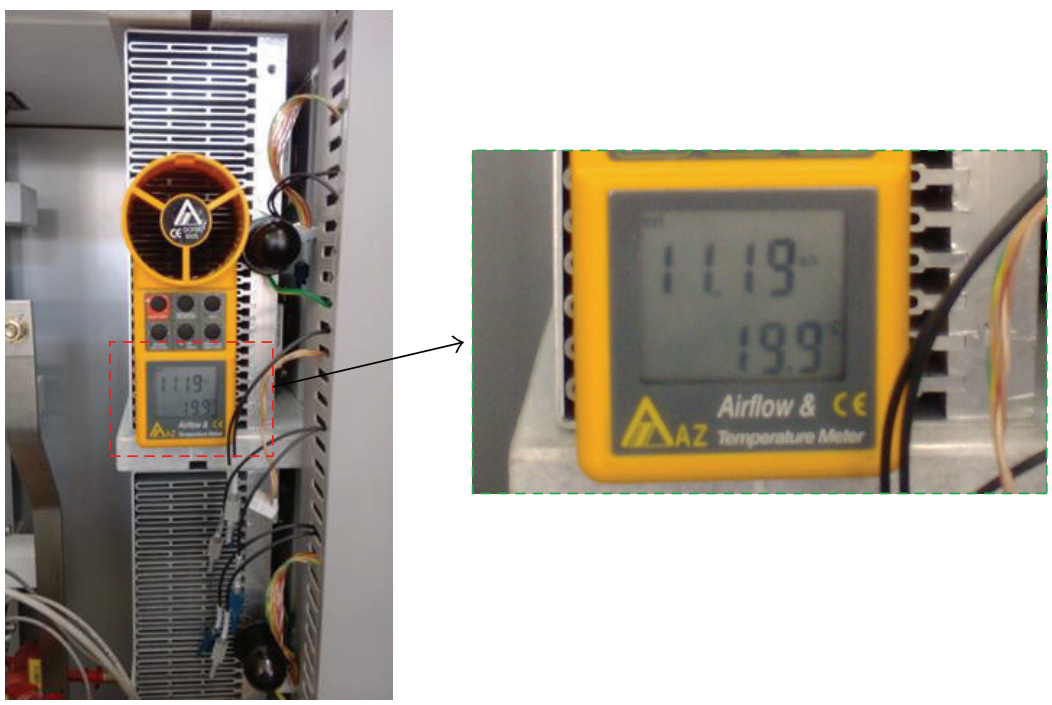

FIGURE 22: Experiment wind speed of heatsink inlet.

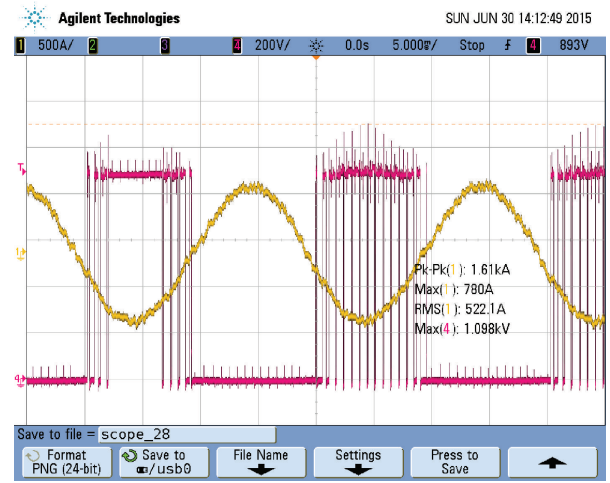

Figure 23: Switching point of two modulations.

the DPWM dual-mode modulation can not only decrease power loss but also keep good control performance, which also proved the effectiveness of the proposed algorithm.

\section{Conclusion}

In accordance with the special application of NPC three-level inverter, the DPWM dual-mode modulation was proposed

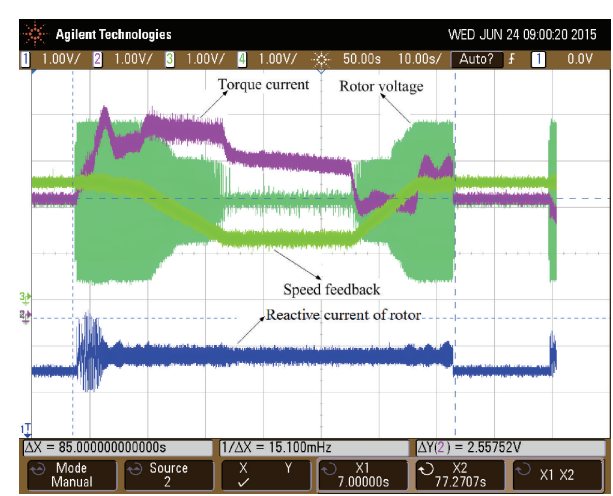

FIGURE 24: Single ascension cycle waveform of hoist based on dualmode modulation.

in this paper to solve the overheating problem of mine hoist under continuous working mode. The proposed modulation can not only decrease the power loss of power devices but also keep good control performance. Finally, simulation and experiment proved that the proposed algorithm can decrease the surface temperature of power devices and substrate temperature by $5^{\circ} \mathrm{C}$ and $8^{\circ} \mathrm{C}$, respectively, which also proved the effectiveness of the proposed algorithm. 


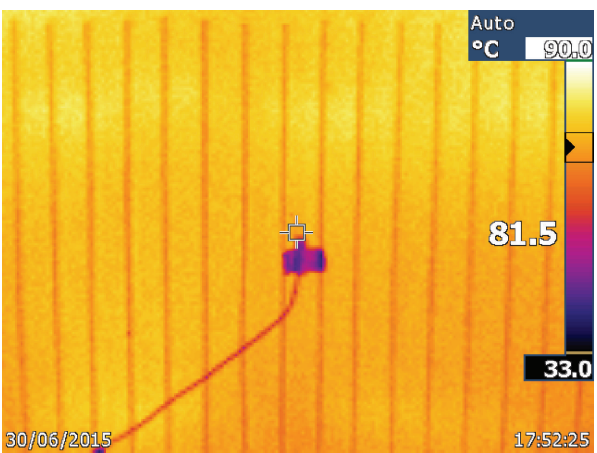

(a) Substrate temperature of heatsink based on SVPWM

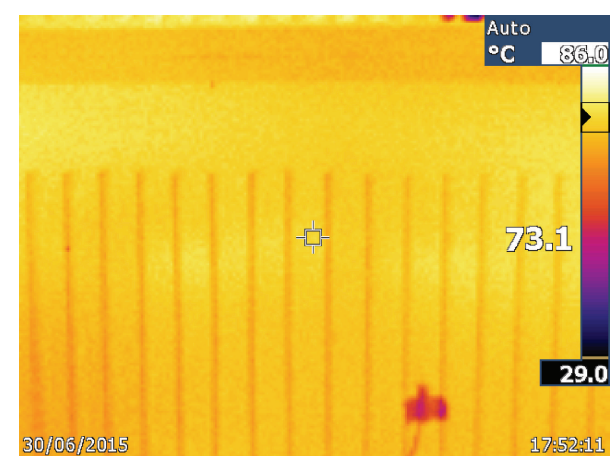

(b) Substrate temperature of heatsink based on DPWM

FIGURE 25: Substrate temperature of heatsink.

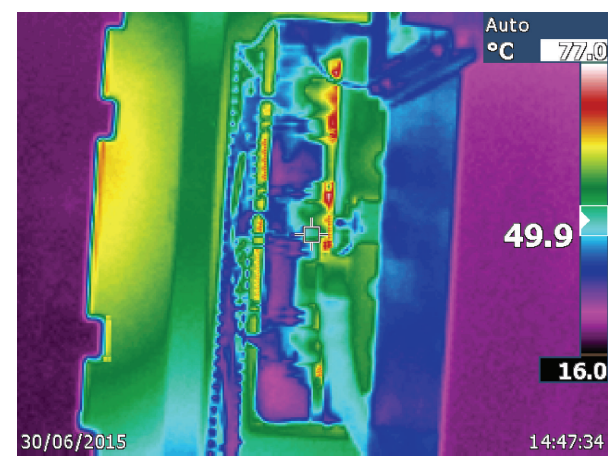

(a) Temperature of acceleration stage based on SVPWM

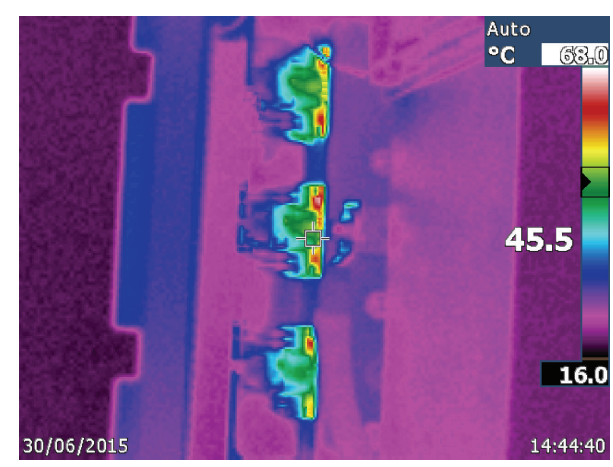

(b) Temperature of acceleration stage based on DPWM

FIGURE 26: Temperature of acceleration stages.

\section{Competing Interests}

The authors declare that they have no competing interests.

\section{References}

[1] J. H. Seo, C. H. Choi, and D. S. Hyun, "A new simplified spacevector PWM method for three-level inverters," IEEE Transactions on Power Electronics, vol. 16, no. 4, pp. 545-550, 2001.

[2] W. Jiang, Q. Wang, Q. Chen, and X. Shi, "SVPWM strategy for three-level inverter based on svpwm strategyfor two-level inverter," Transactions of China Electrotechnical Society, vol. 24, no. 1, pp. 108-114, 2009.

[3] A. K. Gupta and A. M. Khambadkone, "A simple space vector PWM scheme to operate a three-level NPC inverter at high modulation index including overmodulation region, with neutral point balancing," IEEE Transactions on Industry Applications, vol. 43, no. 3, pp. 751-760, 2007.

[4] O. Ojo, "The generalized discontinuous PWM scheme for threephase voltage source inverters," IEEE Transactions on Industrial Electronics, vol. 51, no. 6, pp. 1280-1289, 2004.

[5] Y. Wu, M. A. Shafi, A. M. Knight, and R. A. McMahon, "Comparison of the effects of continuous and discontinuous PWM schemes on power losses of voltage-sourced inverters for induction motor drives," IEEE Transactions on Power Electronics, vol. 26, no. 1, pp. 182-191, 2011.

[6] S. An, X. Sun, Y. Chen, Y. Zhong, and B. Ren, "A new generalized implementation method of discontinuous PWM," Proceedings of the CSEE, vol. 32, no. 24, pp. 59-66, 2012.

[7] Z. Zhang, O. C. Thomsen, and M. A. E. Andersen, "Discontinuous PWM modulation strategy with circuit-level decoupling concept of three-level neutral-point-clamped (NPC) inverter," IEEE Transactions on Industrial Electronics, vol. 60, no. 5, pp. 1897-1906, 2013.

[8] A. M. Hava, R. J. Kerkman, and T. A. Lipo, "A high-performance generalized discontinuous PWM algorithm," IEEE Transactions on Industry Applications, vol. 34, no. 5, pp. 1059-1071, 1998.

[9] P. Mao, S.-J. Xie, and Z.-G. Xu, "Switching transients model and loss analysis of IGBT module," Proceedings of the Csee, vol. 30, no. 15 , pp. $40-47,2010$.

[10] F. Krismer and J. W. Kolar, "Accurate power loss model derivation of a high-current dual active bridge converter for an automotive application," IEEE Transactions on Industrial Electronics, vol. 57, no. 3, pp. 881-891, 2010.

[11] A. D. Rajapakse, A. M. Gole, and P. L. Wilson, "Electromagnetic transients simulation models for accurate representation of switching losses and thermal performance in power electronic 
systems," IEEE Transactions on Power Delivery, vol. 20, no. 1, pp. 319-327, 2005.

[12] H. Jianhui, L. Jingeng, Z. Jibin, and T. Jiubin, "Losses calculation of IGBT module and heat dissipation system design of inverters," Transactions of China Electrotechnical Society, vol. 24, no. 3, pp. 159-163, 2009.

[13] M. H. Bierhoff and F. W. Fuchs, "Semiconductor losses in voltage source and current source IGBT converters based on analytical derivation," in Proceedings of the IEEE 35th Annual Power Electronics Specialists Conference (PESC '04), pp. 28362842, IEEE, Aachen, Germany, June 2004.

[14] C. Quan, W. Qunjing, J. Weidong, and H. Cungang, "Analysis of switching losses in diode-clamped three-level converter," Transactions of China Electrotechnical Society, vol. 23, no. 2, pp. 68-75, 2008.

[15] W. Qunjing, C. Quan, J. Weidong, and H. Cungang, "Analysis of conduction losses in neutral-point-clamped three-level inverter," Transactions of China Electrotechnical Society, vol. 22, no. 3, pp. 66-70, 2007.

[16] T. J. Kim, D. W. Kang, Y. H. Lee, and D. S. Hyun, "The analysis of conduction and switching losses in multi-level inverter system," in Proceedings of the IEEE Annual Power Electronics Specialists Conference-PESC Record, vol. 3, pp. 1363-1368, 2001.

[17] I. Swan, A. Bryant, P. A. Mawby, T. Ueta, T. Nishijima, and K. Hamada, "A fast loss and temperature simulation method for power converters, part II: 3-D thermal model of power module," IEEE Transactions on Power Electronics, vol. 27, no. 1, pp. 258268, 2012.

[18] W. Jing, Study on Power Device Losses of High-Power ThreeLevel Converter, University of Mining and Technology, Xuzhou, China, 2010.

[19] W. U. N. Fernando, L. Papini, and C. Gerada, "Converter temperature regulation with dual mode control of fault-tolerant permanent magnet motors," in Proceedings of the 4th Annual IEEE Energy Conversion Congress and Exposition (ECCE '12), pp. 1902-1908, Raleigh, NC, USA, September 2012.

[20] L. I. Ning, Y. Wang, and Z. Wang, "A double modulation wave carrier-based PWM strategy for three-level neutral point clamped converter," Power System Technology, vol. 38, no. 3, pp. 707714, 2014.

[21] K. Tian and M. Wang, "Three-level double-group doublemodulation-wave carrier-based PWM method," Proceedings of the Chinese Society of Electrical Engineering, vol. 30, no. 30, pp. 55-61, 2010.

[22] Y. Zongbin, Key technology research of high power three-level double-fed adjustable speed mine hoist [Ph.D. thesis], China University of Mining and Technology, 2010. 


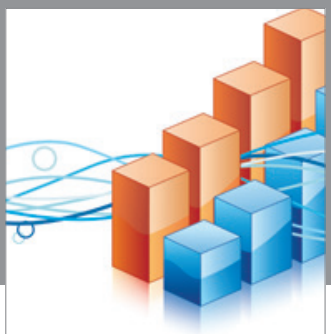

Advances in

Operations Research

vatem alat4

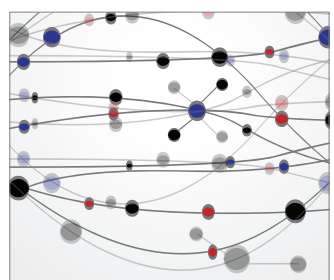

\section{The Scientific} World Journal
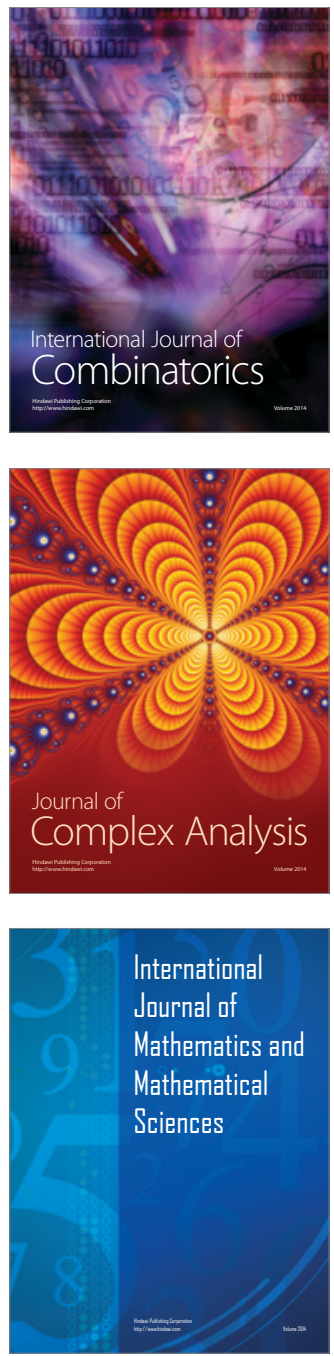
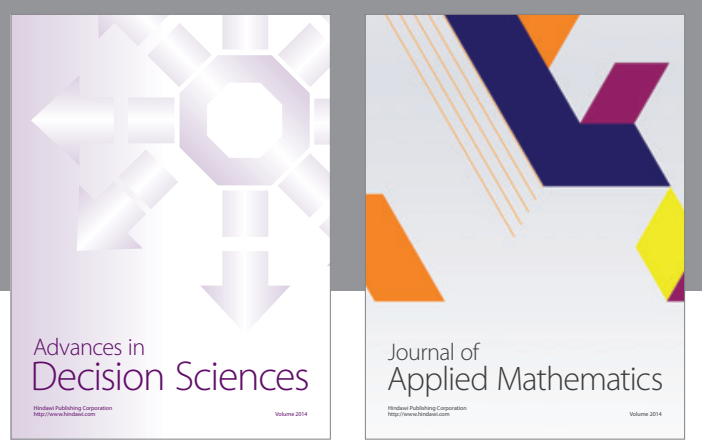

Algebra

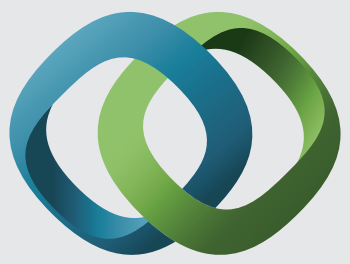

\section{Hindawi}

Submit your manuscripts at

http://www.hindawi.com
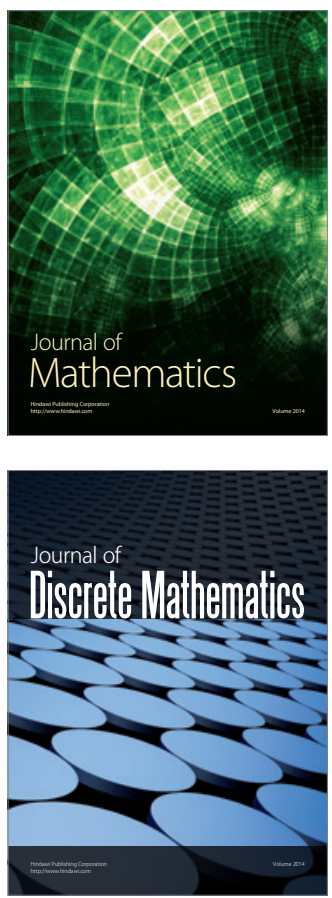

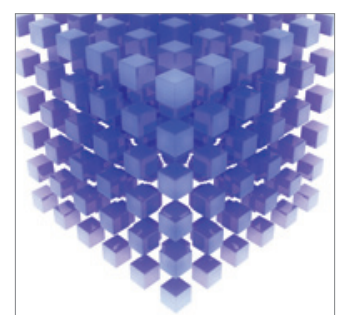

Mathematical Problems in Engineering
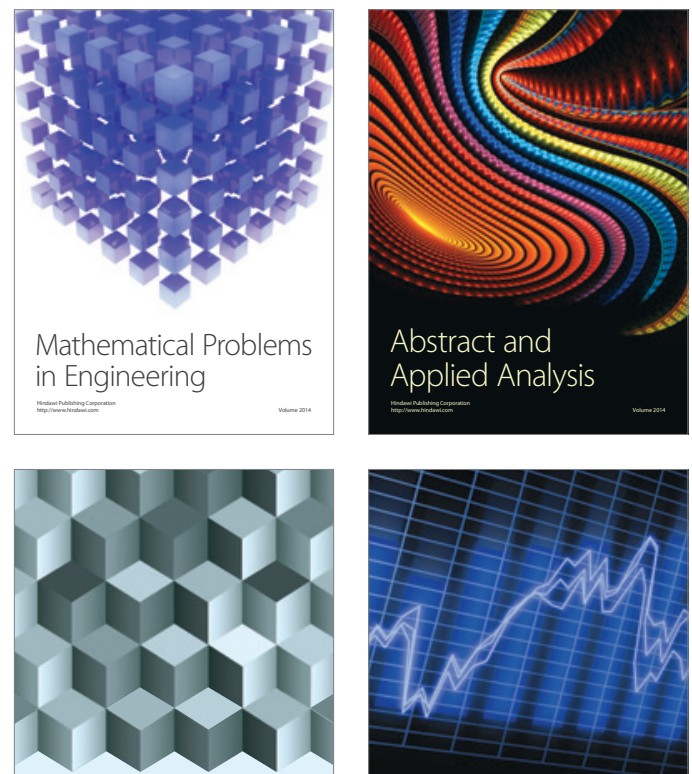

Journal of

Function Spaces

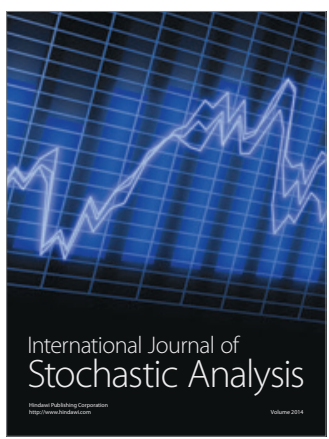

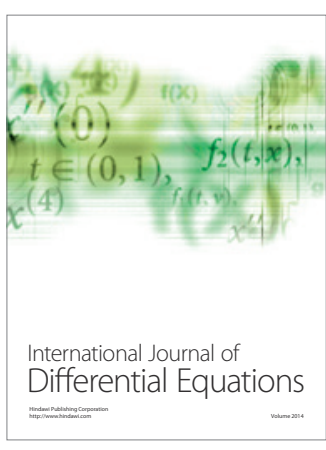
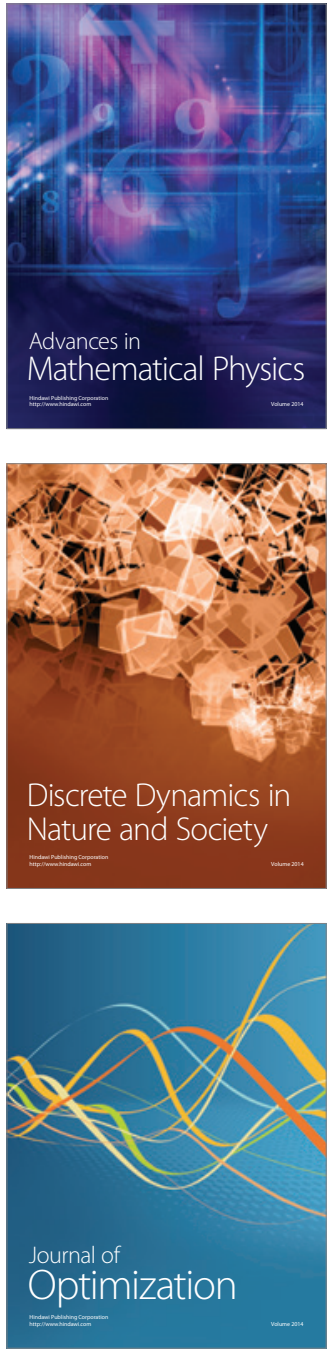